\title{
Effects of dietary methionine levels and L-carnitine supplementation on performance and egg quality parameters of layers
}

\author{
M. Daşkıran¹, A.G. Önol², Ö. Cengiz ${ }^{2,3}$, O. Tatlı and M. Sarı ${ }^{2}$ \\ ${ }^{1}$ Johnson \& Johnson Corporate Science and Technology \\ 410 George Street, New Brunswick, 08901, NJ, USA \\ ${ }^{2}$ Adnan Menderes University, Faculty of Veterinary Medicine, \\ Department of Animal Nutrition and Nutritional Diseases \\ 09016 Aydin, Turkey
}

(Received 7 August 2008; revised version 11 April 2009; accepted 6 November 2009)

\begin{abstract}
Effects of dietary carnitine supplementation ( 0 and $150 \mathrm{mg} / \mathrm{kg} \mathrm{L}$-carnitine) on performance and egg quality parameters of layers in late laying period (from 62 to 72 weeks) fed maize-soyabean meal based diets with different methionine levels $(0.26$ vs $0.40 \%)$ were investigated. A RCBD with $2 \times 2$ factorial arrangement was applied. Eight replicates of the four dietary treatments (3 layers in each cage, a total of 32 cages) were randomly distributed into blocks. The study period was 10 weeks and ninety six 62-week-old Nick Chick white layers were used. In the study, dietary carnitine supplementation did not affect egg production, feed consumption and feed efficiency. However, dietary methionine below requirement level either numerically (the first 5 week from 62 to 67 th weeks and overall 10-week period) or statistically $(\mathrm{P}<0.05)$ (last 5 week from 67 to 72 th weeks) reduced egg production and feed efficiency. Similar to performance data, dietary carnitine supplementation had no impact on egg, egg yolk, and egg shell weights, however, the reduction in dietary methionine level had negative impacts on these parameters as early as 4th week of the study. Neither carnitine nor methionine improved corrected yolk and egg shell weight, yolk colour and egg shell thickness, however, both egg shape index and Haugh unit were affected by dietary methionine levels $(\mathrm{P}<0.05)$. In summary, carnitine supplementation did not affect layer performance and egg quality whereas dietary methionine deficiency significantly reduced layer performance and egg quality in late laying period and the effect was more visible towards the end of the study.
\end{abstract}

KEY WORDS: layer, nutrition, methionine, L-carnitine, performance, egg quality

\footnotetext{
${ }^{3}$ Corresponding autor: e-mail: ozcancen@gmail.com
} 


\section{INTRODUCTION}

Carnitine is a water-soluble quaterner amine ( $\beta$-hydroxy $\gamma$-trimethylaminobutyrate) with 161.2 molecular weight. Two natural stereoisomeric forms of carnitine are D- and L-carnitine and between these two forms, only L-carnitine is physiologically active (McDowell, 1989). Most plant-origin feedstuffs are poor L-carnitine sources whereas animal origin feedstuffs contain considerably high levels of L-carnitine. L-carnitine levels of fish, meat and bone $(40 \% \mathrm{CP})$, and feather meals are $85-145,150$ and $125 \mathrm{mg} / \mathrm{kg}$ respectively. On the other hand, L-carnitine levels of maize, wheat and soyabean meals are very low and within the range of 5-10, 3-12 and $0-10 \mathrm{mg} / \mathrm{kg}$, respectively (Personal communication with Robert G. Teeter, 2005).

Carnitine has beneficial effects on animal performance by enhancing resistance to metabolic diseases, preventing some diseases, strengthening immune system, and playing an important role in metabolic and physiological processes (Gropp et al., 1994; Mast et al., 1999; Carrol and Core, 2001). Having similar effects of vitamins, carnitine takes part in many metabolic functions in organism, such as lipid catabolism and energy production (Walter, 2000; Carrol and Core, 2001). Carnitine is an endogenous betain derivate of $\beta$-hydroxy butyrate, found in the structure of human, animal, plant and some microorganisms in various levels (Bremer, 1983).

Poultry diets are composed mainly of maize and soyabean and plant products are low in carnitine. Nevertheless, it is generally accepted that endogenous L-carnitine synthesis together with bird's dietary intake should be sufficient for normal functions. Methionine and lysine are usually the most important limiting amino acids in poultry nutrition and are frequently supplemented in the formulated diets. Carnitine can be biosynthetized endogenously from these two amino acids. When diets are not supplemented with these two amino acids, the chicken may not be able to synthesize adequate amounts of carnitine (Arslan, 2006).

Most of the studies testing the effects of dietary L-carnitine on poultry have used meat-type chicken as experimental animal. Although the results of these studies have revealed no L-carnitine effect on broiler performance (Cartwright, 1986; Leibetseder, 1995; Daşkıran and Teeter, 2001; Xu et al., 2003), others indicated a reduction in carcass fat (Daşkıran and Teeter, 2001; Xu et al., 2003) or mortality (Daşkıran and Teeter, 2001). In layers, a 4\% increase in hatchability and an increase in egg yolk carnitine level was reported with $50-100 \mathrm{mg} / \mathrm{kg}$ dietary L-carnitine supplementation (Leibetseder, 1995). In the light of the studies using various farm animal and fish species, it can also be concluded that carnitine can be an essential dietary substance in cases when there is insufficient biosynthesis 
in growing animals, the diet is rich in oil sources and inadequate in L-carnitine, and production level is high (Frenkel and McGarry, 1980).

In addition, continious selection of broilers and layers for better feed efficiency and egg production alter their nutrient requirements and some of the nutrients previously considered as non-essential may become essential. Therefore, reevaluating the L-carnitine requirement of poultry becomes a necessity. Although there are quite a few broiler studies evaluating dietary L-carnitine requirement, only a few studies have been conducted to evaluate the L-carnitine requirements of high producing layers (Rabie et al., 1997; Richter, 1998), particularly in late laying period.

The objective of this study was to evaluate the effects of dietary methionine level and L-carnitine supplementation on performance and egg quality parameters of hens fed maize-soyabean meal based diets with no animal origin feeds inclusion in late laying period.

\section{MATERIAL AND METHODS}

\section{Experimental design and diets}

A $2 \times 2$ factorial design was implemented in a randomized complete block design in the study. Factors investigated in the study were two levels of dietary L-carnitine supplementation $(0$ and $150 \mathrm{mg} / \mathrm{kg}$ ) and two dietary methionine levels $(0.26$ and $0.40 \%)$. A total of ninety six 62 -week-old white Nick Chick layers were used as experimental animals. Birds were randomly distributed in 32 cages, each containing 3 birds. Each one of four treatment groups had 24 birds distributed in 8 cages (replicates). Replicates were randomly distributed into 8 blocks and each block consisted of four adjacent cages. Initial liveweight of the birds were similar.

Experimental diets were comprised of feeds obtained from a commercial feedmill and were maize-soyabean meal based. Dietary methionine level for (-) control group was achieved by removing crystalline DL-methionine (\% 99 methionine, BASF Company Ltd., Gunsan, Korea) from the (+) control group and replacing it with ground maize. Both $(+)$ and (-) control groups for methionine were then divided into two and either 0 or $150 \mathrm{mg} / \mathrm{kg}$ L-carnitine (\% 50 carnitine, Lohmann Animal Health, Cuxhaven, The Netherlands) were added into these two portions. Lysine and methionine levels of diets were calculated according to Feedstuffs Reference Issue and Buyers Guide (2005). Experimental diets and their composition are presented in Table 1. 
Table 1. Composition of experimental diets

\begin{tabular}{lrrrr}
\hline & \multicolumn{4}{c}{ Experimental diets } \\
\cline { 2 - 5 } Item & - control & $\begin{array}{c}\text { - control }+ \\
\text { L-carnitine }\end{array}$ & + control & $\begin{array}{r}\text { + control + } \\
\text { L-carnitine }\end{array}$ \\
\hline Feeds, \% & & & & \\
maize, ground & 64.34 & 64.34 & 64.20 & 64.20 \\
soyabean meal & 22.00 & 22.00 & 22.00 & 22.00 \\
vegetable fat & 1.00 & 1.00 & 1.00 & 1.00 \\
calcium carbonate & 9.00 & 9.00 & 9.00 & 9.00 \\
dicalcium phosphate & 3.16 & 3.16 & 3.16 & 3.16 \\
salt & 0.25 & 0.25 & 0.25 & 0.25 \\
vitamin-mineral premix ${ }^{1}$ & 0.25 & 0.25 & 0.25 & 0.25 \\
DL-methionine & 0.00 & 0.00 & 0.14 & 0.14 \\
L-carnitine, mg/kg & 0.00 & 150.00 & 0.00 & 150.00 \\
Calculated analysis & & & & \\
metabolizable energy, kcal/kg & 2800 & 2800 & 2796 & 2796 \\
protein, \% & 15.92 & 15.92 & 16.04 & 16.04 \\
methionine, \% & 0.26 & 0.26 & 0.40 & 0.40 \\
lysine, \% & 0.78 & 0.78 & 0.78 & 0.78 \\
Ca, \% & 3.84 & 3.84 & 3.84 & 3.84 \\
available phosphorus, \% & 0.42 & 0.42 & 0.42 & 0.42 \\
\hline
\end{tabular}

${ }^{1}$ Kavimix VM 23+15/5: supplied per 1 kg of diet; IU: vit. A 12 000, vit. $\mathrm{D}_{3} 2$ 400; mg: vit. E 30, vit. $\mathrm{K}_{3} 2.5$, vit. $\mathrm{B}_{1} 3$, vit. $\mathrm{B}_{2} 7$, vit. $\mathrm{B}_{6} 4$, vit. $\mathrm{B}_{12} 0.015$, nicotinamide 40 , calcium D-pantotenate 8 , folic acid 1, D-biotin 0.045 , vit. C 50, choline chloride 125 , canthaxanthin 1.5 , apo-carotenoic acid ester 0.5, Mn 80, Fe 40, Zn 60, Cu 5, I 0.4, Co 0.1, Se 0.15, antioxidant 10

\section{Experimental procedures}

Birds were housed in California type cage system. The dimensions of each cage was $42 \times 50 \mathrm{~cm}$. A 16-h light: 8 -h dark lighting programme was implemented throughout the study. The duration of the experiment was 10 week following a 6-week adaptation period and covered the time period from beginning of May to mid-July. Feed and water were provided for ad libitum consumption throughout the study. Birds were checked twice a day for feed availability and mortality and any unexpected event was recorded in data capture forms. Egg production data were recorded daily at $5 \mathrm{p} . \mathrm{m}$. while feed consumption data were recorded every other week. Egg weight and internal and external egg quality parameters were measured using daily total production of eggs every other week. There were only 2 mortalities during the experiment and number of birds in each cage was taken into consideration while computing daily and weekly egg production, feed consumption and feed conversion data. Egg and egg shell weights (Scaltec, $\pm 0.01 \mathrm{~g}$ ), egg shell thickness (Mitutoya, Dial Thickness Gage No: $7360, \pm 0.01 \mathrm{~mm}$ ), egg yolk colour (Roche Yolk Colour Fan) and other egg quality data were recorded every other week from the total daily collection of eggs once they were hold at room temperature for 
$24 \mathrm{~h}$. The average of the two measurements of thick-albumen height together with egg weight were used to compute the Haugh unit score for each individual egg according to Haugh (1937) as follows:

$$
\text { Haugh units }=100 \times \log \left(\mathrm{T}-1.7 \times \mathrm{W}^{0.37}+7.57\right) .
$$

\section{Statistical analysis}

Data were analysed using the General Linear Models procedure of the SAS (version 6.03, SAS Institute Inc. Cary, NC, 1988). Once the raw data were processed and all variables were computed for each experimental unit (either cage or bird depending on the variable), analysis of variance was applied to the data to determine whether or not there is any difference among dietary treatment groups. When a difference was detected among treatment means, Duncan test was applied to separate the treatment means (Steel et al., 1997). Based on the experimental design implemented, blocks were included in the statistical model whenever a significant block effect was noticed.

\section{RESULTS}

Effects of feeding maize-soyabean meal based diets with different levels of methionine supplemented with or without L-carnitine on egg production, daily feed intake and feed conversion ratio of layers in late laying period are presented in Table 2. Egg production data indicated that birds fed recommended levels of dietary methionine $(0.40 \%)$ had higher feed consumption throughout the study and the increase in feed consumption was significant in the second half of the study (Table 2).

Effects of maize-soyabean meal based diets with dietary methionine levels of 0.26 and $0.40 \%$ supplemented with or without L-carnitine on egg, egg yolk and egg shell weights of layers in late laying period are given in Table 3. In Table 4 , corrected egg yolk weight, egg yolk colour, egg shell:egg weight ratio, egg shell thickness, shape index and Haugh unit were presented. Dietary carnitine supplementation had no effect on egg, egg yolk and egg shell weights, however, low dietary methionine level reduced forementioned parameters as early as 4th week of the study (Table 3). In the present study, dietary carnitine and methionine levels did not affect corrected egg yolk weight, egg shell weight, egg yolk colour and egg shell thickness significantly, however, shape index and Haugh unit were affected by methinonine level significantly (Table 4). 
Table 2. Effects of feeding maize-soyabean meal based diets with different levels of methionine supplemented with or without L-carnitine on egg production, daily feed intake and feed conversion ratio of layers in late laying period, weeks

\begin{tabular}{|c|c|c|c|c|c|c|c|c|c|}
\hline \multirow{2}{*}{ Dietary treatment groups } & \multicolumn{3}{|c|}{ Egg production, \% } & \multicolumn{3}{|c|}{ Daily feed intake, $g$} & \multicolumn{3}{|c|}{ Feed conversion $^{1}$} \\
\hline & $62-67$ & $67-72$ & $62-72$ & $62-67$ & $67-72$ & $62-72$ & $62-67$ & $67-72$ & $62-72$ \\
\hline \multicolumn{10}{|l|}{ Methionine, \% L-carnitine, } \\
\hline $0.26 \quad m g / n g$ & 94.81 & 82.08 & 88.70 & 99.1 & 81.3 & 90.2 & 1596 & 1815 & 1706 \\
\hline 0.26 & 91.92 & 82.72 & 88.24 & 91.6 & 77.8 & 84.9 & 1584 & 1967 & 1764 \\
\hline 0.40 & 92.86 & 84.96 & 88.96 & 96.1 & 87.7 & 91.9 & 1561 & 1703 & 1632 \\
\hline 0.40 & 91.73 & 86.76 & 89.32 & 98.5 & 84.2 & 91.4 & 1686 & 1678 & 1682 \\
\hline Pooled SEM & 1.21 & 1.69 & 1.15 & 3.9 & 2.4 & 2.42 & 66.1 & 83.5 & 54.3 \\
\hline \multicolumn{10}{|l|}{ Methionine, \% } \\
\hline 0.26 & 93.36 & 82.40 & 88.47 & 95.5 & 79.6 & 87.5 & 1590 & 1891 & 1735 \\
\hline 0.40 & 92.29 & 85.86 & 89.14 & 97.3 & 85.9 & 91.6 & 1623 & 1691 & 1657 \\
\hline \multicolumn{10}{|l|}{ L-carnitine, $m g / k g$} \\
\hline 0 & 93.83 & 83.52 & 88.83 & 97.6 & 84.5 & 91.0 & 1579 & 1759 & 1669 \\
\hline 150 & 91.83 & 84.74 & 88.78 & 95.2 & 81.0 & 88.1 & 1635 & 1822 & 1723 \\
\hline \multicolumn{10}{|l|}{ ANOVA } \\
\hline \multicolumn{10}{|l|}{ Probability } \\
\hline L-carnitine & NS & NS & NS & NS & NS & NS & NS & NS & NS \\
\hline methionine $\mathrm{x}$ L-carnitine & NS & NS & NS & NS & NS & NS & NS & NS & NS \\
\hline
\end{tabular}

At the end of the study, mortality rate was not affected by the dietary supplementation of methionine and carnitine $(\mathrm{P}>0.05)$.

\section{DISCUSSION}

It is known that L-carnitine plays an important role in lipid metabolism and it has the potential to induce some desirable modifications in poultry products. In this study, dietary L-carnitine supplementation did not affect egg production, feed consumption and feed conversion rate. Results associated with L-carnitine supplementation in the present study were in agreement with those of Yalçın et al. (2004) who expressed that supplementation of L-carnitine at dose of $100 \mathrm{mg} / \mathrm{kg}$ to layer hen and quail diets had no effect on feed consumption, egg weight, and feed conversion rate. Also, Leibetseder (1995) has stated that the addition of a standard layer's ration with either $500 \mathrm{mg}$ L-carnitine or $500 \mathrm{mg}$ nicotinic acid, or a combination of both compounds, did not affect egg production, feed intake, body weight during the early laying period in thermoneutral conditions. 


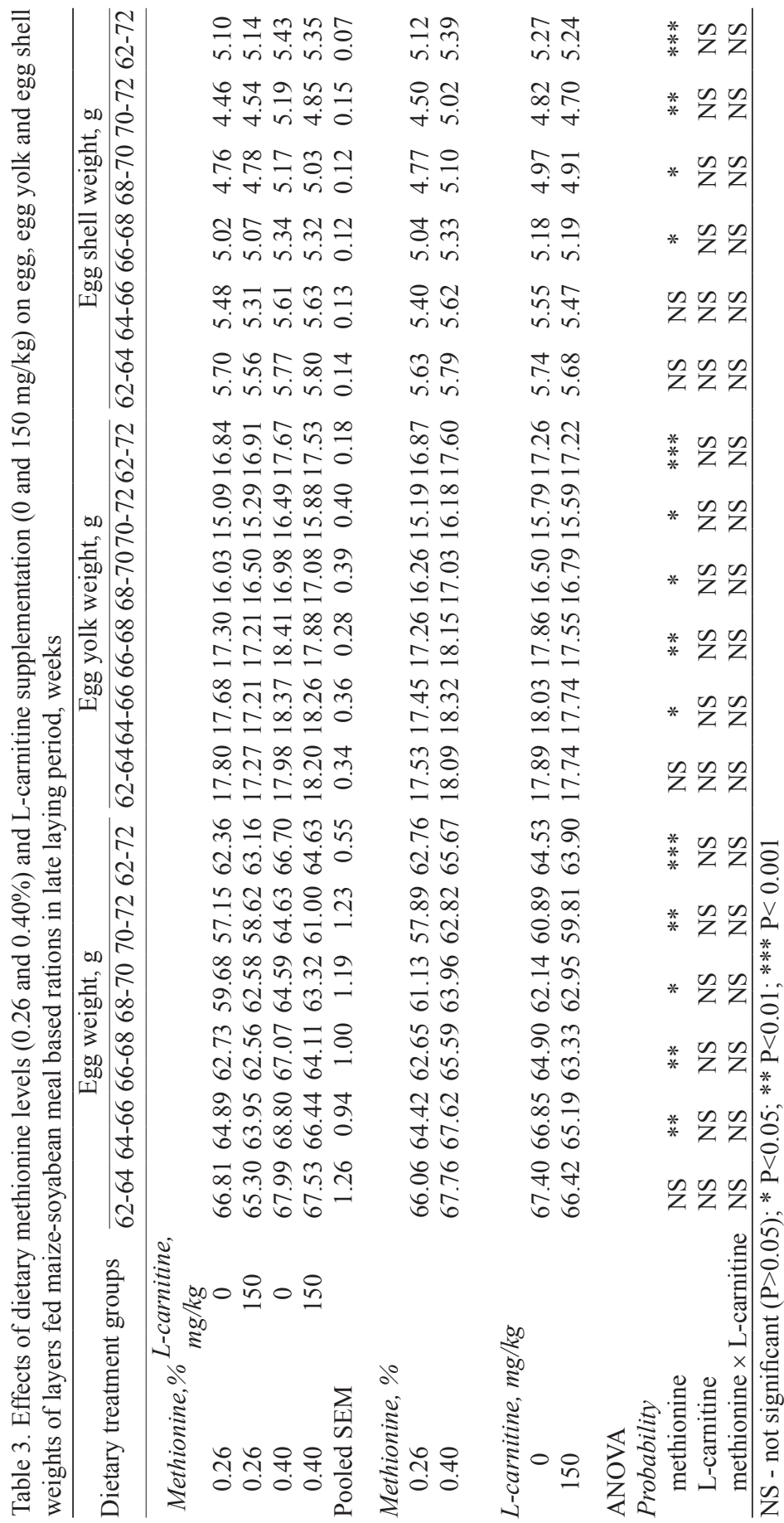




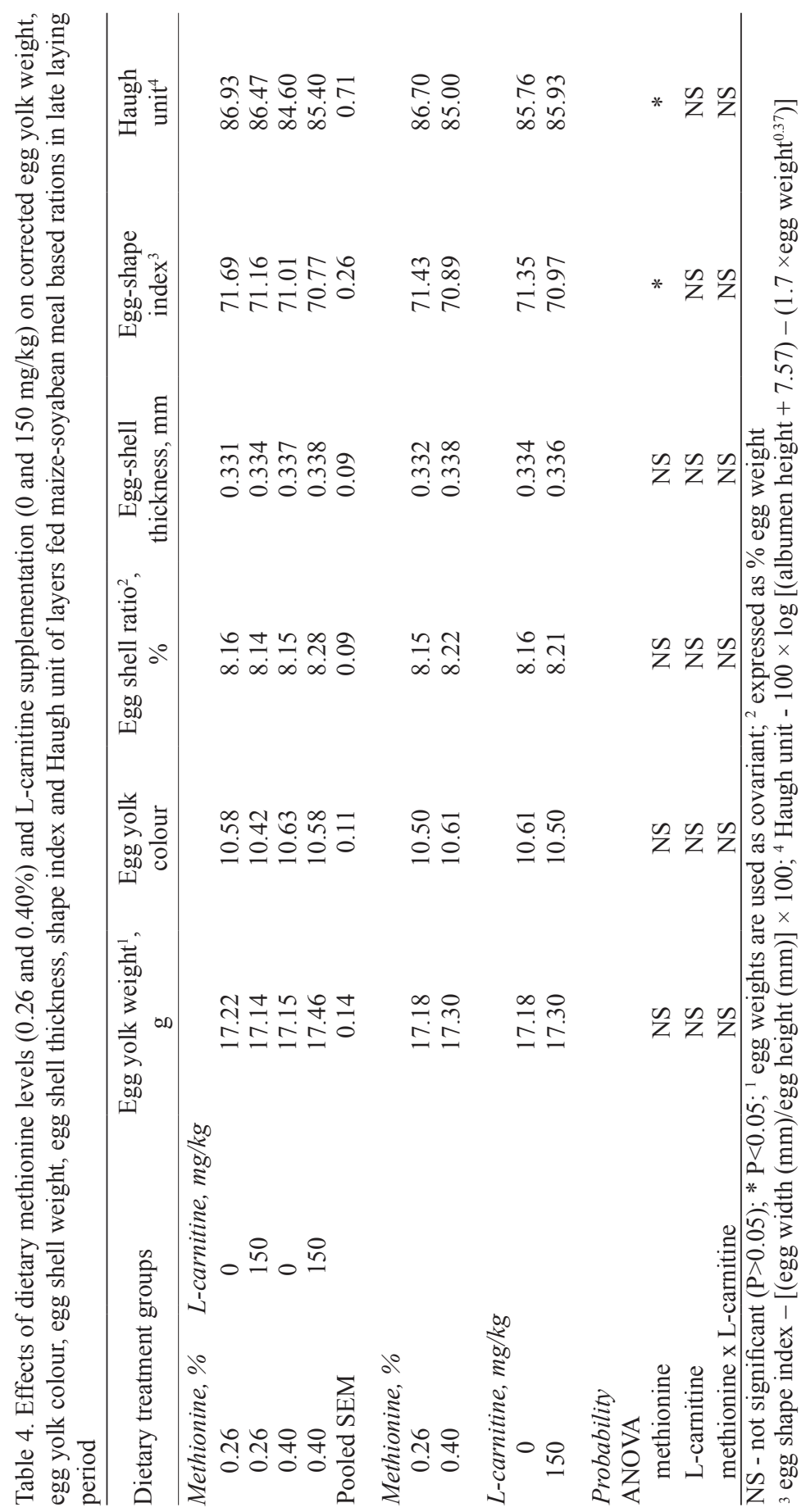


However, in his trial yolk L-carnitine content was significantly higher in the supplemented groups. In addition, some studies have also reported no effect of supplemental carnitine on feed consumption, egg production and feed conversion ratio (Rabie et al., 1997; Çelik et al., 2004). In this study, lowering dietary methionine level from recommendation level $(0.40 \%)$ to $0.26 \%$, on the other hand, reduced egg production and feed conversion ratio as expected. The reduction in egg production and feed conversion ratio was either numeric (from 62nd to 67 th and from 62nd to 72 nd weeks) or significant ( $\mathrm{P}<0.05$; from 67 th to 72nd weeks). As supporting this results Harms et al. (1998) suggested that the intake of methionine controls the amount of egg output, and the hens consume energy to meet the requirement for this amount of egg output. Similar results were reported from previous studies associated with carnitine and its' precursors (methionine and lysine) in poultry diets. In a study conducted on fish, piglets and quail, Schuhmacher et al. (1993), reported that carnitine was appear to be effective in improving body weight gain and feed conversion ratio, mainly in groups with diets marginally deficient in lysine and methionine plus cystine, respectively. The influence of low and high dietary contents of lysine and methionine requirements ( $20 \%$ below or above recommended levels, respectively) on body weight gain, abdominal fat and carnitine content in some tissues was determined by Iben et al. (1991) in broiler chickens. The highest body weight was achieved in groups with optimum dietary contents of the two amino acids. In groups with low lysine and methionine supplementation, the abdominal fat content was higher than that in other groups.

Regards to production data, birds received recommended levels of methionine had higher feed consumption during the study and the increase in feed consumption was significant $(\mathrm{P}<0.05)$. In this study, dietary carnitine and methionine levels had no effect on corrected egg yolk weight, egg shell weight, egg yolk colour and egg shell thickness. On the other hand, shape index and Haugh unit were significantly affected by methinonine level. In this trial, improved albumen quality was occured in supplemented hens, probably due to higher metabolic rate in the magnum and/or a higher activity of the shell gland. The quality of the albumen is mainly dependent on the amount of ovomucin, especially $\beta$-ovomucin, secreted by the magnum. It is reported that $\beta$-ovomucin is largely responsible for the gelatinous traits of the thick albumen gel (Anonymous, 2000). It could, therefore, be speculated that L-carnitine may play a role in the synthesis or secretion of $\beta$-ovomucin by promoting metabolizable energy generation in the magnum. The increase of albumen might be useful for the nutritional point of view and also for improving storage time. Williams (1992) concluded that, excluding disease, the single most important factor affecting albumen quality of freshly-laid egg 
is the age of the bird that laid it. Nutritional factors can modify egg quality by virtue of their transport into the egg, by inducing metabolic changes that result in the synthesis of compounds which find their way into the egg, or by changing the transport characteristics of the membranes involved in formation of the egg components (Hurwitz, 1987). Findings associated with carnitine supplementation were similar to previous studies. Rabie et al. (1997) fed graded levels of carnitine $(50-500 \mathrm{mg} / \mathrm{kg}$ ) to $65-73$ weeks old layers and observed significant improvements in egg white height and Haugh unit, but not performance (egg production rate, mean egg weight, daily feed intake, egg mass and feed conversion) and egg shell quality. Performance, egg shell and internal egg quality results are in agreement with Çelik et al. (2004) who concluded L-carnitine did not affect the growth performance (body weight gain, feed consumption), the laying performance (egg mass and egg weight), the shell quality (weight, thickness, and egg shape index) and the yolk quality (weight and colour score) in layers. They also concluded that the relative albumen weight and height were significantly increased by supplementary L-carnitine $(50 \mathrm{mg} / \mathrm{kg})$ in drinking water. Richter et al. (1997) found that supplementation of carnitine had no effect on feed consumption and feed conversion ratio, but had decreased egg yield and lipid content of egg yolk numerically.

In fact, reports on the effects of dietary L-carnitine on egg production and egg quality of laying hens are limited and contradictory. Leibetseder (1995) has reported that egg hatchability increased from 83 to $87 \%$ and from 82.4 to $85.3 \%$ in broiler breeders supplemented by L-carnitine at 50 and $100 \mathrm{mg} / \mathrm{kg}$ diet, respectively. In Japanese quails, supplementation with L-carnitine $(500 \mathrm{mg} / \mathrm{kg}$ diet) alone or combined with vitamin C (500 mg/kg diet) in diet did not improve growth and carcass yield, however, egg production was significantly enhanced by L-carnitine (Bayram et al., 1999).

\section{CONCLUSIONS}

Different responses to supplementary carnitine are obtained from various studies mainly due to the variations in the species, age, sex, nutrient composition of the diet, levels of L-carnitine in the diet and other environmental conditions. In the current study, data revealed that feeding methionine deficient diets to the hens at late laying period resulted in reduced performance and affected some egg quality parameters as expected and these changes were more pronounced as the experiment progressed. Dietary carnitine supplementation, on the other hand, had no effect on hen performance and egg quality in this experiment. 
However, carnitine requirement may be increased under certain circumstances such as various stress conditions and where diet lacks animal-origin protein sources. Previous research indicated a beneficial effect of carnitine supplementation on egg quality parameters and hatchability. Therefore, further research on high producing laying hens is needed to better understand the optimum carnitine requirement under various production conditions .

\section{REFERENCES}

Anonymous, 2000. Egg-grading Manual. U.S. Department of Agriculture. Agricultural Marketing Service, Agricultural Handbook, No. 75

Arslan C., 2006. L-Carnitine and its use as a feed additive in poultry feeding: a review. Rev. Mèd. Vèt. 157, 134-142

Bayram İ., Akınc1 Z., Uysal H., 1999. Effects of dietary supplementation of L-carnitine and vitamin C on growth and laying performance in Japanese quail (Coturnix coturnix Japonica), (in Turkish).

J. Vet. Fac. Yüzüncü Y1l Uni. 10, 32-37

Bremer J., 1983. Carnitine: metabolism and functions. Physiol. Rev. 63, 1420-1480

Carrol M.C., Core E., 2001. Carnitine: a review. Comp. Cont. Edu. Pract. Vet. 23, 45-52

Cartwright A.L., 1986. Effect of carnitine and dietary energy concentration on body weight and body lipid of growing broilers. Poultry Sci. 65, Suppl. 1, 21 (Abstr.)

Çelik L.B., Tekeli A., Özturkcan O., 2004. Effects of supplemental L-carnitine in drinking water on performance and egg quality of laying hens exposed to a high ambient temperature. J. Anim. Physiol. Anim. Nutr. 88, 229-233

Daskiran M., Teeter R.G., 2001. Effects of dietary L-carnitine (Carniking ${ }^{\circledR}$ ) supplementation on overall performance and carcass characteristics of seven-week-old broiler chickens. Oklahoma Agricultural Experiment Station, Animal Science Research Report. http://www.ansi.okstate. edu/research/2001rr/35/35.htm

Frenkel R.A., McGarry J.D., 1980. Carnitine Biosynthesis Metabolism, and Functions. Academic Press Inc. New York, NY

Gropp J.M., Schumacher A., Schweigert F.J., 1994. Recent research in vitamin nutrition with special emphasis to vitamin A, $\beta$ - carotene and L-carnitine. In: Proceedings of the Meeting of the Arkansas Nutrition Conference. Fayetteville, AR: Arkansas Poultry Federation, pp. 124-134

Harms R.H., Russell G.B., Harlow H., Ivey F.J., 1998. The influence of methionine on commercial laying hens. J. Appl. Poultry Res. 7, 45-52

Haugh R.R., 1937. The Haugh unit for measuring egg quality. US Egg Poultry Mag. 43, 572-573

Hurwitz S., 1987. Effect of nutrition on egg quality. In: R.G. Wells, C.G. Belyavin (Editors). Egg Quality - Current Problems and Recent Advances. Poultry Science Symposium. London. Butterworths Ltd., No. 20, pp. 235-254

Iben C., Meinhart S., Leibetseder J., 1991. Carnitine in broilers. Part 1: Effects of carnitine precursors. Wien. Tierarztl. Monatsschr. 78, 403-407

Larbier M., Leclercq B., 1994. The egg, and feeding of the laying hen. In: J. Wiseman (Editor). Nutrition and Feeding of Poultry. Nottingham, Nottingham University Press, pp. 169-197

Leibetseder J., 1995. Studies on the effects of L-carnitine in poultry. Arch. Anim. Nutr. 48, 97-108

Mast J., Buyse J., Goddeeris B.M., 1999. Dietary L-carnitine supplementation increases antigenspecific immunoglobulin $\mathrm{G}$ production in broiler chickens. Brit. J. Nutr. 83, 161-166 
McDowell L.R., 1989. Vitamins in Animal Nutrition. Academic Press Inc. San Diego, CA

Rabie M.H., Szilagyi M., Gippert T., 1997. Effects of dietary L-carnitine on the performance and egg quality of laying hens from 65-73 weeks of age. Brit. J. Nutr. 78, 615-623

Richter V.G., Schlumbohm C., Baumgartner M., Ochrimenko W.I., 1998. Untersuchungen zur Wirksamkeit von L-Carnitin bei Legehennen. Arch. Geflugelk. 62, 1-6

Schuhmacher A., Eissner C., Gropp J.M., 1993. Carnitine in fish, piglets and quail. In: G. Flachowsky, R. Schubert (Editors). Vitamine und weitere Zusatzstoffe bei Mensch und Tier. Friedrich-Schiller Universität, Jena (Germany), pp. 407-412

Steel R.G.D., Torrie J.H., Dickey D.A., 1997. Principles and Procedures of Statistics: A Biometrical Approach. 3rd Edition. McGraw-Hill Publishing. New York, NY

Walter P., 2000. L-carnitine - a vitamin-like substance for functional food. Ann. Nutr. Metab. 44, 75-96

Williams K.C., 1992. Some factors affecting albumen quality with particular reference to Haugh unit score. World Poultry Sci. J. 48, 5-16

Xu Z.R., Wang M.Q., Mao H. X., Zhan X.A., Hu C.H., 2003. Effects of L-carnitine on growth performance, carcass composition and metabolism of lipids in male broilers. Poultry Sci. 82, 408-413

Yalçın S., Ergün A., Özsoy B., Yalçın S., Erol H., Onbaşılar İ., 2006. The effects of dietary supplementation of L-carnitine and humic substances on performance, egg traits and blood parameters in laying hens. Asian-Austr. J. Anim. Sci. 19, 1478-1483 